\title{
On the calcination of hydrous oxide of chromium
}

\section{Krüger}

To cite this article: M. Krüger (1845) On the calcination of hydrous oxide of chromium, Philosophical Magazine Series 3, 26:171, 181-182, DOI: 10.1080/14786444508562693

To link to this article: http://dx.doi.org/10.1080/14786444508562693

册 Published online: 30 Apr 2009.

Submit your article to this journal 준

Џ Article views: 2

Q View related articles $₫$ 
charcoal and chlorine, is yellow, very fusible and volatile. Perchloride of niobium prepared in the same manner is colourless, nonfusible, and but very slightly volatile.

When dry ammonia is passed over perchloride of tantalum, the gas is absorbed, but very slowly, and the perchloride becomes less heated than is the case with the other liquid and volatile metallic chlorides placed under the same circumstances. This is not owing to the perchloride not possessing great affinity for the ammonia; but the new combination formed envelopes the perchloride of tantalum, and prevents the reaction from extending further. If this new compound be heated, metallic tantalum is obtained, and hydrochlorate of ammonia disengaged. The whole of the hydrochlorate of ammonia is removed by washing with water. On heating the metal with access of air, it is converted into tantalic acid with evolution of light. The reduction of tantalum requires a much higher temperature than that of titanium under similar circumstances. Metallic tantalum presents the appearance of black crusts. Water bas no action on it.

Perchloride of niobium submitted to the action of dry ammonia becomes yellow, with considerable evolution of heat, because from its being infusible it offers a greater surface to the action of the ammonia. On applying heat to the new compound it immediately becomes black, with disengagement of hydrochlorate of ammonia. The reduction is effected at a much lower temperature than that of the tantalum. On washing it with water to free it from hydrochlorate of ammonia, the water passes clear as long as it contains any of that salt ; but when the metal is nearly pure the water becomes turbid. This inconvenience is avoided by adding a few drops of alcohol to the water. When heated in the air the metal burns with evolution of light into white niobic acid. Nitric acid and aqua regia are without action on it even on boiling; but it is attacked, with disengagement of red vapours, by a mixture of nitric and hydrofluoric acids. Tantalum behaves in the same manner towards these acids.

If the same atomic composition be admitted for tantalic and niobic acids, the weight of niobium will be higher than that of the tantalum*.-From the Chemicul Gazette for Jan. 15th, 1845.

\section{ON THE CALCINATION OF HYDROUS OXIDE OF CHROMIUM.} BY M. KR̈̈GER.

It is well known that when hydrated oxide of chromium ( $\ddot{\mathrm{Cr}})$ is heated to low redness in a platina crucible, it loses its water, becomes strongly incandescent, and loses its sulubility in dilute acids. Several interesting circumstances have however remained entirely unnoticed in this experiment.

If hydrated oxide of chromium be heated only to a little above $392^{\circ} \mathrm{F}$. in contact with the air, it loses all its water and becomes almost black, it is however brown, when reduced to fine powder; if

* We are also informed by Mr. W. Francis that another new metal called Ruthenium has recently been discovered in the platinum residues, by Prof. Claus of Kasan.-R. 'T. 
it be more strongly heated, incandescence then begins, and the oxide becomes green. If however the oxide which has become black be heated in a small retort, it will be observed that a great disengagement of gas occurs both before and during ignition; this gas is oxygen, and the oxide becomes at the same time green.

Hydrated oxide of chromium is completely converted by heat in contact with air into peroxide, $\ddot{C} \ddot{v}$, which at a low red heat is changed, with incandescence, into oxide of chromium. M. Krïger finds the peroxide to consist of 63.7 metal and $36 \cdot 3$ oxygen.

This peroxide is a peculiar componnd, and does not contain chromic acid ; if it be mixed with chloride of sodium and the mixture be treated with sulphuric acid, chlorine is given out without the formation of any trace of the red chromate of chloride of chromium. When it is boiled with hydrochloric acid, the peroxide yields chlorine, and if heated with sulphuric acid it gives oxygen; the best method of making these experiments is to precipitate hydrate of oxide of chromium from dilute solutions by ammonia. If the precipitation be effected in a boiling solution, it is obtained in a more compact state, which renders it but slightly soluble in diluted acids.

If to a solution of bichromate of potash there be added a neutral solution of sulphate of chromium and then ammonia, there is obtained a brown precipitate, from which, as shown by M. Mons, all the sulphuric acid may be removed by very long washing; there remains only hydrate of oxide of chromium; according to this chemist this precipitate is not peroxide of chromium, but chromate of basic oxide of chromium $\dddot{\mathrm{C}} \mathrm{r}+\ddot{\mathrm{C}}$.

If however the brown precipitate be washed only until sulphuric acid cannot be discovered in the filtered liquor, and then after drying in the air it is treated with chloride of sodium and fuming sulphuric acid, no chromate of oxide of chromium is disengaged, but merely chlorine, proving that the precipitate is merely peroxide of chromium, but unquestionably in the state of hydrace.

It is not decomposed even by long treatment with water into chromic acid and oxide of chromium. If peroxide of chromium obtained in this manner be heated, it loses water, and is converted, by a stronger beat, into oxide, with the disengagement of oxygen and with ignition.-Journ. de Pharm. et de Ch. December, 1844.

PREPARATION OF FELRATE OF SODA AND OF BARYTES, \&C.

M. Fremy states that, after having formed ferrate of potash in the mode described (Phil. Mag., January, p. 81), he endeavoured to procure ferrate of soda by the same means; but he found that it was impossible to obtain ferrate of soda by acting upon iron by nitrate of soda in a Hessian crucible, this nitrate appearing to be much more fixed in this case than the nitrate of putash; the former salt is decomposed slowly, and the free soda attacks the crucible.

Ferrate of soda was rcadily obtained in the moist way by passing chlorine into concentrated soda containing suspended hydrate of peroxide of iron. 